\title{
Vivências de plantar e comer: a horta escolar como prática educativa, sob a perspectiva dos educadores'
}

\section{Experiences of growing and eating: school gardens as educational practice, from educators' perspective}

\author{
Denise Eugenia Pereira Coelho \\ Universidade de São Paulo. Faculdade de Saúde Pública. Programa \\ de Pós-graduação em Saúde Pública. São Paulo, SP, Brasil. \\ E-mail: deepcoelhoœgmail.com

\section{Cláudia Maria Bógus} \\ Universidade de São Paulo. Faculdade de Saúde Pública. Departa- \\ mento de Prática de Saúde Pública. São Paulo, SP, Brasil. \\ E-mail: claudiabðusp.br
}

\section{Resumo}

No cenário social contemporâneo, o resgate do vínculo do alimento com a natureza é central para o desenvolvimento de ações educativas na área de alimentação e nutrição. Nesse sentido, hortas escolares podem ser uma importante estratégia pedagógica, contando com um aprendizado baseado no contato direto com o alimento e a natureza. Este estudo buscou compreender a produção de sentidos na alimentação, entre os educadores, decorrente do envolvimento com a horta na escola. Foi uma pesquisa qualitativa, com base na hermenêutica filosófica, em que foram feitas entrevistas em profundidade com professores, funcionários e diretores de três escolas municipais de Embu das Artes. O desenvolvimento da horta produziu sentidos que dizem respeito: ao aprendizado horizontal e à troca de experiências; à vivência prática de conteúdos teóricos; ao cuidado, pelas experiências subjetivas e intersubjetivas; ao estreitamento de vínculos com a natureza, com as pessoas e com a comida. A horta escolar é uma estratégia pedagógica que abre diversas possibilidades para se pensar a relação com a alimentação.

Palavras-chave: Agricultura Urbana; Educação Alimentar e Nutricional; Saúde Escolar.

\section{Correspondência}

Denise Eugenia Pereira Coelho

Rua Wanderlei, 1723, Perdizes. São Paulo, SP, Brasil. CEP $05011-002$.

1 Apoio financeiro: Bolsa de mestrado do Conselho Nacional de Desenvolvimento Científico e Tecnológico (CNPq). 


\section{Abstract}

Given the contemporary social scene, rebuilding the bond between food and nature is an important perspective for developing educational practices within the area of food and nutrition. This way, school gardens can be an important educational strategy, with possibilities to produce learning by direct contact with food and nature. This study aimed to understand the production of meanings related to food, among educators, due to their involvement with school gardens. It was a qualitative study, based on philosophical hermeneutics. For data collecting, in-depth interviews were conducted with teachers, staff, and the heads of three public schools in the city of Embu das Artes, São Paulo, Brazil. The development of the school gardens allowed participants to experience meanings related to: horizontal learning and exchange of experiences; practical learning; building of health care, through subjective and intersubjective experiences; strengthening of bonds with nature, with people and with food. School gardens are an important pedagogical proposal which opens many possibilities to think the relationship with food.

Keywords: Urban Agriculture; Food and Nutrition Education; School Health.

\section{Introdução}

Os comportamentos e tradições alimentares são dinâmicos e a história da alimentação mostra como as mudanças nos modos de viver contribuíram para conformar os alimentos consumidos e a forma de prepará-los (Contreras; Gracia, 2011). Esse dinamismo do ato de comer na atualidade pode ser pensado na perspectiva das transformações que a alimentação vem sofrendo em decorrência das mudanças sociais, econômicas e culturais da sociedade contemporânea (Fonseca et al., 2011).

Essas mudanças nos modelos alimentares têm impacto nas identidades e relações sociais que se recompõem tanto no meio rural como urbano e se refletem no cotidiano da alimentação de indivíduos e comunidades (Suremain; Katz, 2009). Como parte dessas transformações, pode-se destacar: a mundialização da alimentação que, associada à globalização, é acompanhada pela perda do território nacional como referência para o alimento; a industrialização da produção, transformação e distribuição dos alimentos, contribuindo para mudanças na relação entre meio rural e urbano, com modificação nos modos de vida e nos vínculos estabelecidos com os alimentos (Poulain, 2004).

Como consequência dessas transformações, configura-se o "alimento moderno": o desenraizamento geográfico associado à industrialização corta o vínculo entre alimento e natureza, tendo como consequência a padronização dos alimentos; por outro lado, não há uma identidade ou qualidade simbólica desse alimento, justamente pela ausência de uma origem identificável (Fonseca et al., 2011; Poulain, 2004). O alimento moderno é um alimento "dessocializado", ou seja, há "uma diluição de vínculos de reconhecimento com a comida, assim como de sua capacidade de dizer quem somos" (Suremain; Katz, 2009), fenômeno também chamado de "gastro-anomia".

Para Fischler (apud Poulain, 2004), o conceito da "gastro-anomia" se refere a três fenômenos concomitantes: superabundância alimentar, diminuição dos controles sociais e a multiplicação dos discursos sobre alimentação. Destaca-se que a diminuição dos controles sociais, ou seja, as escolhas e decisões que 
antes eram tomadas em grupo passam a ser tomadas prioritariamente na esfera individual, fenômeno associado à dessocialização - ou desritualização - da alimentação. Além disso, a multiplicação dos discursos configura a chamada "cacofonia alimentar”, uma composição de discursos contraditórios e dissonantes, que são pano de fundo para tais escolhas individuais (Poulain, 2004).

Assim, o enfraquecimento dos controles sociais, o individualismo e a industrialização da alimentação, ao contribuírem para o rompimento do vínculo com o alimento, geram um contexto de "ansiedade alimentar" e as informações relacionadas aos alimentos não parecem diminuir essa sensação de medo ou ansiedade, pois, se por um lado elas fornecem mais critérios de escolhas, por outro se constrói uma noção de novas áreas ainda desconhecidas (Poulain, 2004).

Essas análises convergem com a teoria da sociedade de risco: a alimentação não escapa à reflexividade da modernidade e à configuração da sociedade de risco - que é o estágio de desenvolvimento mais avançado da modernidade em que as ameaças produzidas pela sociedade industrial começam a aparecer, em uma transição que ocorre de forma indesejada e despercebida pelo próprio dinamismo da modernização (Beck, 1995). O desconhecimento é o meio motor da modernidade reflexiva (Beck, 2010).

Assim, no campo da alimentação, a questão do risco "se caracteriza pelo crescente número de escândalos alimentares e conflitos de controle e regulação, bem como pelo grande número de discursos conflituosos" (Portilho; Castañeda; Castro, 2011, p. 100). E diante das incertezas e consequências indesejadas (ou não previstas) do avanço da modernidade, a questão central é a da tomada de decisão com os riscos. E apesar da socialização dos riscos e seus efeitos, as respostas que têm sido produzidas são individualizadas (Beck, 2010), o que pode ser identificado também no campo da alimentação na construção de "uma ação política individualizada, local e orientada para uma solução concreta em relação aos riscos que percebem" (Portilho; Castañeda; Castro, 2011, p. 105).

No campo da nutrição ainda se tem uma estrutura educativa baseada na divulgação de informa- ções científicas, segundo uma estrutura discursiva normativa de mudança de hábito (Santos, 2012), em que a difusão de informações sobre benefícios e malefícios de alimentos e nutrientes reforçam tal caráter, desconsiderando os determinantes do processo saúde-doença e o saber popular (Castro et al., 2007).

Com o objetivo de apoiar as ações de Educação Alimentar e Nutricional (EAN) nos diversos setores de modo a integrar estratégias mais amplas para promoção da qualidade de vida da população e de um campo comum de reflexões e práticas, o "Marco de Referência em Educação Alimentar e Nutricional para as políticas públicas" aponta que a EAN:

deve fazer uso de abordagens e recursos educacionais problematizadores e ativos que favoreçam o diálogo junto a indivíduos e grupos populacionais, considerando todas as fases do curso da vida, etapas do sistema alimentar e as interações e significados que compõe o comportamento alimentar. (Brasil, 2012, p. 23)

Em trabalho anterior à publicação do Marco Referencial, Santos (2012) analisou as práticas educativas no campo da alimentação e da nutrição, reconhecendo que ainda há uma lacuna entre discurso e prática, pois se por um lado fala-se de uma mudança na perspectiva teórico-metodológica das ações, para ser dialógica e crítica, por outro há pouco aprofundamento teórico e a prática ainda se mantém predominantemente estruturada por uma dimensão técnica e normativa.

Para Boog (2010) a escola é um espaço destacado para desenvolver ações de EAN. Veiga-Neto (2007) ao discutir a escola, coloca o seguinte questionamento: "se a escola moderna sempre esteve implicada na constituição da Modernidade e se, agora, é a própria Modernidade que está em crise, qual o futuro da escola?" (p. 102). O autor parte do entendimento de que a escola foi e continua sendo a principal instituição encarregada de construir o mundo moderno, devendo pelo menos garantir a manutenção das conquistas fundamentais da modernidade. Para Libâneo (2007), a escola é um espaço de síntese entre a cultura experienciada pelos alunos e a cultura 
formal, e essa relação deve ocorrer dentro de seus modos de vida e origens sociais.

Santos (2012) sugere a construção de novas perspectivas para as práticas educativas. Apesar das hortas escolares não serem uma novidade no cenário da educação em saúde ou da EAN, ainda há pouca discussão sobre suas abordagens e possibilidades educativas (Iuliano, 2008).

\section{Objetivo}

O objetivo deste trabalho foi compreender a produção de sentidos na alimentação entre educadores, decorrente do envolvimento com a horta na escola. Especificamente, pretende-se compreender como a experiência pessoal de envolvimento com plantio e a experiência de participação na horta escolar contribuem para a construção de uma relação com a comida.

\section{Métodos}

Este é um estudo qualitativo e optou-se quanto ao caminho metodológico pela perspectiva da hermenêutica filosófica, para compreender experiências e vivências - subjetivas e intersubjetivas - de educadores envolvidos nas hortas escolares. A hermenêutica trabalha com uma análise complexa de passado e futuro, analisando o ciclo de interpretações como experiência vivida e interpretações históricas que continuamente se influenciam (Liamputtong; Ezzy, 2005).

Marcada pelas contribuições de Heidegger, a questão do método é recolocada sob a ontologia, em que a questão passa a ser não apenas como saber, mas "qual o modo de ser desse ser que só existe compreendendo" (Ricoeur, 2008, p. 37). Gadamer, segundo Debesay, Nåden e Slettebø (2008), coloca a verdade como abertura à experiência, tratando a hermenêutica como uma abordagem e não como um método em princípio, em que sua principal intenção é revelar as condições que facilitam a compreensão, como um objetivo do "ser-no-mundo". Assim, compreender faz parte do estar lançado no mundo e a verdade é experiência, experiência que ganha sentido ao ser compartilhada - assim, são compartilhamentos que geram verdade (Grondin, 2003).
O município de Embu das Artes está localizado na região metropolitana de São Paulo, e suas experiências mais recentes de agricultura urbana tiveram como um dos pontos de partida o Programa Fonte Escola (PFE), iniciado em 2009 por uma organização não governamental local. A equipe do PFE realizou atividades com grupos de crianças das escolas públicas da região, desenvolveu cursos de formação em hortas escolares agroecológicas, voltados para educadores, e assistência técnica e pedagógica nas escolas (Frug et al., 2013; SEAE, [2013?]). Em Embu das Artes, nove escolas municipais (E.M.) desenvolveram hortas a partir do curso de formação, e atualmente três ainda mantêm essas hortas.

Foram realizadas diversas visitas às escolas em agosto de 2013, com o objetivo de se conhecer a realidade local, a forma de realização das atividades nas hortas e o modo de envolvimento dos educadores. O Quadro 1 apresenta uma breve caracterização das escolas.

Dado que as três escolas têm situações distintas entre si, no que tange à forma de desenvolvimento e responsabilização pela horta, optou-se por incluir as três no estudo. A seleção dos atores-chave foi intencional, no sentido de serem aqueles que tinham as condições necessárias para fornecer adequadamente as informações relevantes para o estudo, tentando-se abranger diferentes perfis de cargo e de envolvimento nas atividades.

Os sujeitos da pesquisa formalizaram o aceite em participar pela assinatura do Termo de Consentimento Livre e Esclarecido. Para o desenvolvimento da pesquisa, foram considerados os princípios éticos que norteiam a pesquisa envolvendo seres humanos, conforme a Resolução do Conselho Nacional de Saúde $n^{0}$ 466, de 12 de dezembro de 2012, sendo este estudo aprovado pelo Comitê de Ética em Pesquisa da Faculdade de Saúde Pública da Universidade de São Paulo (Of. COEP/o76/13, protocolo $n^{0} 2.338$ ).

Para a coleta de dados, foram feitas entrevistas em profundidade com os atores-chave selecionados. Segundo Minayo (2008), as entrevistas semiestruturadas podem ser consideradas como entrevistas em profundidade, pois variam apenas em grau de abertura em relação à entrevista aberta, por serem 
orientadas por um roteiro, mas com abertura a outras questões que a aprofundem. Elas têm sido utilizadas para o estudo de "significados subjetivos e tópicos complexos" (Szymanski, 2008, p. 10), com o objetivo de explorar o processo da gênese dos significados e interpretações (Liamputtong; Ezzy, 2005). Essas entrevistas foram feitas em outubro de 2013, com diretores, professores e funcionários, totalizando oito entrevistados, dos quais sete do sexo feminino e apenas um do sexo masculino, com idades entre 38 e 51 anos. A escolha do olhar desses educadores se deu não apenas por se compreender que são eles que constroem as práticas educativas voltadas aos alunos, mas também são eles os determinantes na aproximação com as famílias e comunidade do entorno.

A análise foi feita sob a perspectiva hermenêutica, sendo que o material foi trabalhado segundo a análise temática de conteúdo, não se considerando categorias a priori. Realizou-se uma leitura flutuante das entrevistas como um primeiro contato e impressão do material transcrito e suas informações. As categorias foram estabelecidas a partir dos temas que foram se construindo.

\section{Quadro I - Caracterização das escolas estudadas}

\begin{tabular}{|l|l|l|l|}
\hline \multirow{2}{*}{ Ensino oferecido } & $\begin{array}{l}\text { E.M. M. } \\
\text { Educação Infantil e Ensino } \\
\text { Fundamental }\end{array}$ & Educação Infantil & Ensino Fundamental \\
\hline Total de alunos & 235 & 180 & 590 \\
\hline $\begin{array}{l}\text { Envolvimento } \\
\text { da comunidade } \\
\text { escolar }\end{array}$ & $\begin{array}{l}\text { Todos os professores e alunos } \\
\text { participam das atividades e há } \\
\text { também outros funcionários } \\
\text { envolvidos. }\end{array}$ & $\begin{array}{l}\text { Todos os professores e alunos } \\
\text { participam das atividades da } \\
\text { horta e há envolvimento das } \\
\text { merendeiras. }\end{array}$ & $\begin{array}{l}\text { Professores participam } \\
\text { das atividades apenas } \\
\text { indiretamente. }\end{array}$ \\
\hline $\begin{array}{l}\text { Inserção da } \\
\text { estrutura na } \\
\text { curricular das } \\
\text { escolas }\end{array}$ & $\begin{array}{l}\text { Há um horário para as } \\
\text { atividades da horta } \\
\text { semanalmente na estrutura } \\
\text { curricular. }\end{array}$ & $\begin{array}{l}\text { Os professores inserem as } \\
\text { atividades da horta nas } \\
\text { disciplinas uma vez por } \\
\text { semana. }\end{array}$ & $\begin{array}{l}\text { Existem as chamadas "Aulas } \\
\text { de horta", semanalmente } \\
\text { para o desenvolvimento das } \\
\text { atividades na horta, que fazem } \\
\text { parte da estrutura curricular. }\end{array}$ \\
\hline $\begin{array}{l}\text { Responsabilidade } \\
\text { pela horta }\end{array}$ & $\begin{array}{l}\text { Há um coordenador de } \\
\text { projetos na escola que é } \\
\text { responsável por projetos que } \\
\text { vão além do currículo escolar, } \\
\text { comó é o caso da horta. }\end{array}$ & $\begin{array}{l}\text { Não há um responsável único } \\
\text { pelas atividades da horta. }\end{array}$ & $\begin{array}{l}\text { Há uma professora que tem } \\
\text { exclusiva responsabilidade } \\
\text { pela horta, que fica } \\
\text { diretamente no espaço e } \\
\text { conduz as atividades com os } \\
\text { alunos. }\end{array}$ \\
\hline
\end{tabular}

\section{Resultados}

\section{Vivências pessoais com a natureza}

As falas revelaram um passado que remete ao contato com a terra, ao cultivo de hortas e a um gosto especial por essa prática.

Os relatos apontaram uma vivência com parentes próximos, especialmente mães, durante a infância, em que se expressa essa relação de cuidado com a terra e os alimentos. Esse contato e conhecimentos práticos, intergeracionais, foram relatados em algu- mas das falas dos educadores: "Quando nós éramos pequenos, assim, eu tinha uns sete, oito anos, a minha mãe fez uma horta em casa, uma horta muito grande, então tinham vários canteiros e assim, a gente plantava, a gente cuidava, a gente colhia" (Educadora, 44 anos, E.M. I.R.).

Além disso, os educadores associaram o gosto pela horta com a experiência de ter vivido ou ainda viver em sítio, em função da proximidade com a natureza: "Eu me criei na roça, então, eu tenho um gosto especial pelo verde, pelo plantar, pelo colher, eu sempre tive" (Educadora, 56 anos, E.M. I.M.I.). Essa 
vivência no meio rural também foi resgatada por meio do alimento, e um dos educadores afirmou que no campo existe um contato diferente com a comida.

Em relação ao aprendizado que a horta proporciona, ela foi reconhecida como um espaço de trocas interpessoais, pois alguns educadores revelaram levar conhecimentos anteriores e experiências pessoais, tanto relacionados ao plantio como aos alimentos em si:

"É uma somatória de experiências e, por exemplo, coisas que eu nunca tinha visto eu fui ver aqui na escola, alguns tipos de verduras que algumas pessoas trouxeram, então acho que é toda uma troca de experiência" (Educador, 43 anos, E.M. M.).

O aprendizado foi também relacionado à origem dos alimentos, decorrência do contato direto com a horta, passando pela experiência do cuidado na produção do alimento:

Assim, de você plantar, ver a sementinha, uma muda pequena que você vai cuidando e depois você colher, você comer, tem a parte da alimentação, eu acho que isso é o que mais me fascina. [...] O pezinho de orégano foi uma coisa que eu só via no saquinho [...]. $\varepsilon$ eu plantei o orégano! (Educadora, 51 anos, E.M. I.M.I.).

Esse e outros depoimentos mostram que a horta contribuiu para mudanças pessoais na alimentação.

\section{Horta e educação alimentar e nutricional}

Os depoimentos anteriores, sobre a experiência pessoal e como os educadores vivenciavam o cuidado com a horta, refletiram-se diretamente na compreensão do papel da horta na escola. As falas trataram da importância de se desenvolver uma horta na escola em que a perspectiva educativa passasse pelo contato e pelo cuidado, com a natureza e com os alimentos.

A escola que tem horta permite estabelecer uma relação diferente com os alimentos, por meio do despertar da curiosidade para sua produção, por meio do conhecimento da cadeia alimentar e a "origem" dos alimentos:
Toda escola deveria ter esse espaço, porque as crianças gostam, porque eu acho que é importante, sai essa visão, principalmente nos centros, que tudo o que a gente compra vem do mercado. Tudo bem, a gente compra no mercado, a gente compra na feira, mas para estar ali no mercado, na prateleira, veio de algum lugar, e eu acho que é bacana trabalhar isso com as crianças. (Educadora, 51 anos, E.M. I.M.I.)

Assim, o envolvimento e a participação das crianças, segundo os educadores, apontou para a construção de uma relação significativa com o alimento que a própria criança produziu, o que acabava sendo um estímulo a experimentá-lo e comê-lo:

Eles plantando uma fruta ou uma verdura é mais interessante porque eles veem o processo, eles acompanham, eles tiveram trabalho para fazer aquilo né, então eu acredito que na cabeça de qualquer criança aquilo merece ser 'puxa, eu plantei, eu vou experimentar', mesmo que ele não goste depois, mas ele experimentou e, em geral, eles gostam. (Educador, 43 anos, E.M. M.)

Além desses aspectos, nas falas dos educadores houve um entendimento do papel da horta como uma estratégia à EAN para uma alimentação mais consciente, possibilitada pelo conhecimento a partir do contato direto com a horta: "quando ele [o aluno] está vivendo, está pondo a mão, está participando, com certeza fixa muito mais e ele aprende muito mais, eu acredito que sim, a horta faz parte sim da educação e da alimentação, nutrição, com certeza" (Educadora, 38 anos, E.M. M.).

Da mesma forma, as atividades na horta possibilitaram também estabelecer uma relação diferente com o meio ambiente, pelo contato direto com a natureza:

Acho que amplia as possibilidades das crianças, acho na relação com o ambiente, de ver lá o que você plantou e colheu. [...] Eles colheram o alface para o almoço especial e depois eles plantaram o alface, então, quer dizer, perceber todo esse ciclo né, eu acho que é uma forma de se inteirar 
da vida, é o ciclo da vida. (Educadora, 43 anos, E.M. M.)

\section{Discussão}

Este estudo revelou que a horta é um espaço participativo que pode ser pensado como um ambiente profícuo de aprendizagem e de produção de cuidado.

A ideia de que a horta seja um espaço de trocas pode apontar a possibilidade de se construir um ambiente de aprendizagem para a comunidade escolar como um todo, em que podem ser trabalhadas capacidades e habilidades, valores e atitudes, sob os mais diversos aspectos do conhecimento, o que de fato é um papel que a escola pode cumprir (Libâneo, 2007).

A horta como espaço de aprendizado e trocas pode ser vista também sob o âmbito da produção de cuidado, diante da perspectiva hermenêutica da saúde, que valoriza a participação ativa dos sujeitos a partir de uma necessária relação dialógica (Ayres, 2007), para a qual os relatos pareceram convergir. É possível dizer, ainda, que a horta possibilita a criação de um espaço participativo que pode contribuir para a promoção da saúde não apenas dos alunos, mas também do corpo de funcionários da escola.

Assim, a horta escolar, que geralmente é estudada como estratégia de EAN direcionada às crianças, apresentou-se como uma forma de educação participativa para funcionários e professores envolvidos, que contribuiu para um maior cuidado em relação à alimentação, para adquirir conhecimentos sobre os alimentos, e também para promover formas de sociabilidade. Nesse sentido, a horta também pode ser entendida como um estímulo ao cuidado, nos termos colocados por Luz (2007), como parte de práticas de sociabilidade, ou revitalização de suas formas tradicionais.

Em relação ao papel da horta como estratégia à EAN, houve uma relação direta com o papel da escola na produção de conhecimento, com atividades que saíam do padrão informativo e possibilitavam práticas educativas que, além de associarem teoria e prática, permitiam trabalhar aspectos sensíveis do conhecimento, contribuindo para a formação de vínculos com o alimento produzido.
Em estudo de intervenção na Austrália, que consistiu no desenvolvimento de uma horta escolar com a participação de alunos de 8 a 13 anos, observou-se o aumento na capacidade de identificar hortaliças e frutas e maior atenção em relação à origem do alimento (Somerset; Markwell, 2009). Outro estudo de intervenção envolvendo crianças de 8 a 11 anos, em Los Angeles (EUA), em que se realizaram aulas em uma horta comunitária, atividades culinárias e aulas com conteúdos relacionados à nutrição, os participantes relataram aumento na preferência por hortaliças e percepção de que os alimentos da horta tinham um gosto melhor do que os comprados no mercado (Gatto et al., 2012).

Outros estudos que também analisaram o desenvolvimento de atividades com horta em espaços educativos, geralmente associadas a atividades culinárias, têm encontrado como resultado, entre crianças e jovens participantes, maior vontade para experimentar hortaliças, maior preferência por seu consumo, maior capacidade de identificá-las, bem como um aumento no consumo de frutas e hortaliças e variedades consumidas (Heim; Stang; Ireland, 2009; Morgan et al., 2010; Ratcliffe et al., 2011).

Essas questões são consonantes com o papel da escola, ou no resgate do papel da escola como produtora de conhecimento, no desenvolvimento de capacidades e habilidades, que valorizam também a dimensão ambiental (Libâneo, 2007).

É possível, assim, por meio da horta, produzir uma relação que faça sentido para as crianças no contato com a produção de alimentos. Isso certamente traz possibilidades às questões e dilemas da alimentação contemporânea, pois rompe com uma padronização e uma alienação características do "alimento moderno" que, sem identidade, não se diferencia um industrializado de uma verdura, no que diz respeito à produção de sentidos - ainda que a posterior experiência culinária seja também chave nesse processo de resgate e construção de sentidos e vínculos com a alimentação (Castro et al., 2007).

Tais falas apontam, ainda, uma educação diferente do que usualmente se constrói no campo da nutrição, pautada essencialmente pela divulgação de informações científicas, com um discurso normativo e comportamental (Castro et al., 2007; Santos, 
2012), e que não passa pelo entendimento da alimentação como uma construção social, imersa nas redes de relações que compõem a cultura e a cultura alimentar como tal.

Diante dos resultados encontrados neste estudo, é essencial destacar o diálogo que estabelecem com o Marco de Referência em Educação Alimentar e Nutricional, dando concretude às proposições voltadas à construção de políticas públicas que deverão se constituir como processos educativos. Nesse sentido cabe destacar alguns dos princípios que apareceram nas falas dos educadores: sustentabilidade social, ambiental e econômica, abordagem no sistema alimentar em sua integralidade, a comida e o alimento como referências, promoção do autocuidado e da autonomia, educação geradora de participação ativa e autonomia (Brasil, 2012).

Em revisão de literatura sobre estudos de intervenção tendo como estratégia a EAN em escolas, Ramos, Santos e Reis (2013) identificaram que, além da baixa quantidade de produção científica na área, o foco geral dos artigos encontrados era o combate e prevenção da obesidade, em que as estratégias educativas privilegiavam palestras, apresentações, o contar histórias e outras dinâmicas lúdicas, mas que, de um modo geral, objetivavam a transmissão de conhecimentos de nutrição. As autoras chamam a atenção para a permanência da perspectiva educativa behaviorista nas estratégias adotadas.

Outra revisão de literatura, que incluiu estudos de intervenção envolvendo hortas com a participação de crianças e adolescentes (de 5 a 15 anos) nos Estados Unidos, analisou o impacto da educação nutricional pela horta segundo os seguintes parâmetros, em relação a frutas, verduras e legumes: consumo, vontade de saborear e preferências (Robinson-O'Brien; Story; Heim, 2009). Como resultado, os autores afirmam que houve aumento na ingestão de frutas, verduras e legumes e maior interesse, ou vontade, de saborear esses alimentos.

Ou seja, as atividades desenvolvidas nas hortas escolares em Embu das Artes, na forma como são entendidas e desenvolvidas, apontam perspectivas para recolocar a EAN como estratégia perante as questões colocadas para a alimentação na contem- poraneidade e a importância do processo de politização da comida (Portilho; Castañeda; Castro, 2011) e de respostas coletivas - não individualizadas (Beck, 2010) - para o que estamos chamando de "ansiedade alimentar" (Poulain, 2004), diante do "mosaico de discursos" contraditórios: morais, dietéticos, identitários, científico, midiático, entre outros.

Segundo Fischler (apud Carvalho; Luz, 2009): "O significado de alimentação saudável não deve ser 'naturalizado', pois é uma construção social que se realiza na prática, no "pensar os alimentos”' (p. 318). Então, apesar de se falar da produção de uma relação diferente com o alimento, por meio da vivência na horta, o discurso científico e normativo de saúde e alimentação aparece também na construção dessa ação educativa.

Assim, em diálogo com as questões apresentadas na introdução, esse contato com os alimentos da horta pode contribuir para construir uma relação diferente do que se tem hoje com os alimentos, com uma simbologia e uma identidade que o diferenciem do alimento padronizado, seja ele industrializado ou não.

Então, segundo a ideia do alimento "moderno", deslocado e industrializado, que não tem mais vínculo com a natureza e é visto como uma mercadoria e teve destruído "parcialmente seu enraizamento natural e suas funções sociais” (Poulain, 2004, p. 51), o desenvolvimento da horta escolar parece contribuir para produzir vínculos com o alimento e com a natureza.

\section{Considerações finais}

Adotando-se a abordagem da pesquisa qualitativa sob o olhar da hermenêutica, buscou-se compreender a vivência de educadores em relação ao envolvimento com hortas escolares e quais sentidos se produzem quanto à alimentação e à escola, desde o âmbito da produção de sentidos do individual ao todo das relações, entendendo que o encontro das experiências pessoais e coletivas torna inseparável a subjetividade da intersubjetividade.

A perspectiva hermenêutica pode fazer emergir vivências do projeto da horta que dão sentido às práticas e processos envolvidos em seu desenvolvimento. Por outro lado, foi interessante perceber como as 
atividades são um reflexo das vivências pessoais, ao mesmo tempo que eles, como participantes ativos, são parte desse processo educativo.

A horta foi reconhecida como um espaço de aprendizado, em que as trocas interpessoais apresentaram uma perspectiva horizontal e dialógica entre os envolvidos, em que todos podem contribuir com seus conhecimentos e experiências na construção do projeto. Sob essa perspectiva, a horta se revelou também um espaço de produção de cuidado, compreendido a partir da participação ativa dos sujeitos e a partir da produção da sociabilidade, resgatando e construindo vínculos de cuidado consigo, com o outro e com a natureza.

Esses resultados são a base para entender como a horta se constitui como uma estratégia de EAN, que é pautada pela participação e contato direto com a horta, bem como por uma noção ampla de cuidado. Assim, diante de ações majoritariamente normativas focadas na mudança de hábito, a horta é uma proposta que pode trabalhar com uma perspectiva dialógica e emancipatória de educação, dentro da escola.

A partir desse horizonte, a EAN parece contribuir para produzir outros sentidos com o alimento e com a natureza. 0 contato com a produção de alimentos, além de propiciar conhecimentos, contribui para a formação de vínculo com esse alimento produzido, o que é rompimento importante em relação ao alimento moderno, padronizado e sem identidade.

Além disso, diante da conformação da alimentação na sociedade de risco, que passa pela ansiedade alimentar, pela profusão de discursos contraditórios, com respostas padronizadas produzidas autobiograficamente, a horta parece representar o fortalecimento de respostas construídas coletivamente.

A escola é espaço de produção de conhecimento, portanto os conteúdos devem ser trabalhados em perspectiva dialógica com as culturas e a experiência de vida da comunidade escolar como um todo, como forma, inclusive, de democratização do conhecimento, questão essencial para uma formação crítica e emancipatória.

Eé nesse aspecto que reside a potencialidade da horta, que naqueles espaços produziu sentidos que dizem respeito: ao aprendizado horizontal e trocas de experiências; ao contato com aquilo que permite a vivência e não apenas conteúdos teóricos racionais; ao cuidado, como valor primordial da existência, pelas experiências subjetivas e intersubjetivas, pelo estreitamento de vínculos, com a natureza, com as pessoas, com a alimentação.

Por fim, cabe destacar que existem diversas possibilidades para se repensar a alimentação na contemporaneidade e as práticas educativas nela envolvidas, e certamente a horta em escolas é uma importante proposta. Em relação às políticas públicas, mostra-se que é possível construir propostas mais integradas às dinâmicas locais e que integrem setores e disciplinas na perspectiva de uma formação cultural ampla, indo ao encontro das orientações do Marco de Referência em Educação Alimentar e Nutricional.

\section{Referências}

AYRES, J. R. C. M. Uma concepção hermenêutica de saúde. Physis, Rio de Janeiro, v. 17, n. 1, p. 43-62, 2007. Disponível em: <http://www.scielo. br/scielo.php?script=sci_arttext\&pid=So103$73312007000100004 \& \operatorname{lng}=p t \& n r m=i s o \& t l n g=p t>$. Acesso em: 8 maio 2015.

BECK, U. A reinvenção da política: rumo a uma teoria da modernização reflexiva. In: GIDDENS, A.; BECK, U.; LASH, S. (Org.). Modernização reflexiva: política, tradição e estética na ordem social moderna. São Paulo: Unesp, 1995. p. 11-71.

BECK, U. Sociedade de risco: rumo a uma outra modernidade. São Paulo: Editora 34, 2010.

BRASIL. Ministério do Desenvolvimento Social e Combate à Fome. Marco de referência de educação alimentar e nutricional para as políticas públicas. Brasília, DF, 2012.

BO0G, M. C. F. Programa de educação nutricional em escola de ensino fundamental de zona rural.

Revista de nutrição, Campinas, v. 23, n. 6, p. 1005-1017, 2010. Disponível em: <http://www. scielo.br/scielo.php?script=sci_arttext\&pid=S141552732010000600007\&lng=pt\&nrm=iso>. Acesso em: 8 maio 2015 .

CARVALHO, M. C. V. S.; LUZ, M. T. Práticas de saúde, sentidos e significados construídos: 
instrumentos teóricos para sua interpretação. Interface, Botucatu, v. 13, n. 29, p. 313-326, 2009. Disponível em: <http://www.scielo.br/ scielo.php?script=sci_abstract\&pid=S1414$32832009000200006 \& \operatorname{lng}=$ pt\&nrm=iso>. Acesso em: 8 maio 2015 .

CASTRO, I. R. R. de et al. A culinária na promoção da alimentação saudável: delineamento e experimentação de método educativo dirigido a adolescentes e a profissionais das redes de saúde e de educação. Revista de Nutrição, Campinas, v. 20, n. 6, p. 571-588, 2007. Disponível em: <http://www.scielo.br/scielo.php?script=sci_arttex t\&pid=S1415-52732007000600001>.

Acesso em: 8 maio 2015.

CONTRERAS, J.; GRACIA, M. Alimentação, sociedade e cultura. Rio de Janeiro: Fiocruz, 2011.

DEBESAY, J.; NÅDEN, D.; SLETTEB $\emptyset$, Å. How do we close the hermeneutic circle? A Gadamerian approach to justification in interpretation in qualitative studies. Nursing Inquiry, v. 15, n. 1, p. 57-66, 20o8. Disponível em: <http://onlinelibrary. wiley.com/doi/10.1111/j.1440-180o.2008.0039o.x/ abstract;jsessionid $=214878452 \mathrm{~A} 53 \mathrm{EF} 12 \mathrm{CEACF} 308$ 14F19AD 7.fo3to4>. Acesso em: 8 maio 2015.

FONSECA, A. B. et al. Modernidade alimentar e consumo de alimentos: contribuições sócioantropológicas para a pesquisa em nutrição. Ciência \& Saúde Coletiva, Rio de Janeiro, v. 16, n. 9, p. 3853-3862, 2011. Disponível em: <http:// www.scielo.br/scielo.php?script=sci_arttext\&pid $=$ S1413-81232011001000021 $>$. Acesso em: 8 maio 2015 .

FRUG, A. et al. Horta escolar: uma sala de aula ao ar livre. Embu das Artes: Sociedade Ecológica Amigos de Embu, 2013.

GATTO, N. M. et al. LA Sprouts: a gardenbased nutrition intervention pilot program influences motivation and preferences for fruits and vegetables in Latino youth. Journal of the Academy of Nutrition and Dietetics, v. 112, n. 6, p. 913-920, 2012. Disponível em: <http:// www.sciencedirect.com/science/article/pii/ S2212267212001268>. Acesso em: 8 maio 2015.
GRONDIN, J. Introdución a Gadamer. Barcelona: Herder, 2003.

HEIM, S.; STANG, J.; IRELAND, M. A garden pilot project enhances fruit and vegetable consumption among children. Journal of the American Dietetic Association, v. 109, n. 7, p. 1220-1226, 2009. Disponível em: <http://www.sciencedirect.com/ science/article/pii/Sooo2822309004581>. Acesso em: 8 maio 2015 .

IULIANO, B. A. Atividades para promoção de alimentação saudável em escolas de ensino fundamental do município de Guarulhos, SP. 2008. 191 f. Dissertação (Mestrado em Saúde Pública) - Faculdade de Saúde Pública da Universidade de São Paulo, São Paulo, 2008.

LIAMPUTTONG, P.; EZZY, D. Qualitative research methods. 2. ed. Oxford: Oxford University, 2005.

LIBÂNEO, J. C. A escola com que sonhamos é aquela que assegura a todos a formação cultural e científica para a vida pessoal, profissional e cidadã. In: COSTA, M. V. (Org.). A escola tem futuro? 2. ed. Rio de Janeiro: Lamparina, 2007.p. 11-22.

\section{LUZ, M. T. Novos saberes e práticas em saúde} coletiva: estudo sobre racionalidades médicas e atividades corporais. 3. ed. São Paulo: Hucitec, 2007.

MINAYO, M. C. S. O desafio do conhecimento: pesquisa qualitativa em saúde. 11. ed. São Paulo: Hucitec, 2008.

MORGAN, P. J. et al. The impact of nutrition education with and without a school garden on knowledge, vegetable intake and preferences and quality of school life among primary-school students. Public Health Nutrition, v. 13, n. 11, p. 1931-1940, 2010. Disponível em: <http:// journals.cambridge.org/action/displayAbst ract? fromPage=online\&aid $=7914927 \&$ fileId $=$ S1368980010000959>. Acesso em: 8 maio 2015.

PORTILHO, F.; CASTAÑEDA, M.; CASTRO, I. R. R. de. A alimentação no contexto contemporâneo: consumo, ação política e sustentabilidade. Ciência \& Saúde Coletiva, Rio de Janeiro, v. 16, n. 1, p. 99-106, 2011. Disponível em: <http://www. scielo.br/scielo.php?script=sci_arttext\&pid=S1413- 
81232011000100014\&lng=pt\&nrm=iso>.

Acesso em: 8 maio 2015.

POULAIN, J.-P. Sociologias da alimentação:

os comedores e o espaço social alimentar.

Florianópolis: UFSC, 2004.

RAMOS, F. P.; SANTOS, L. A. da S.; REIS, A. B. C. Educação alimentar e nutricional em escolares: uma revisão de literatura. Cadernos de Saúde Pública, Rio de Janeiro, v. 29, n. 11, p. 2147-2161, 2013. Disponível em: <http://www.scielosp.org/ pdf/csp/v29n11/o3.pdf >. Acesso em: 8 maio 2015.

RATCLIFFE, M. M. et al. The effects of school garden experiences on middle school-aged students' knowledge, attitudes, and behaviors associated with vegetable consumption. Health Promotion Practice, v. 12, n. 1, p. 36-43, 2011. Disponível em: <http://hpp.sagepub.com/ content/12/1/36.long>. Acesso em: 8 maio 2015.

RICOEUR, P. Hermenêutica e ideologias. 2. ed. Petrópolis: Vozes, 2008.

ROBINSON-O'BRIEN, R.; STORY, M.; HEIM, $\mathrm{S}$. Impact of garden-based youth nutrition intervention programs: a review. Journal of the American Dietetic Association, v. 109, n. 2, p. 273-280, 2009. Disponível em: <http:// www.sciencedirect.com/science/article/pii/ Sooo2822308020440>. Acesso em: 8 maio 2015.

SANTOS, L. A. da S. O fazer educação alimentar e nutricional: algumas contribuições para reflexão. Ciência \& Saúde Coletiva, Rio de Janeiro, v. 17, n. 2, p. 455-462, 2012. Disponível em: <http://www.scielo.br/scielo.php?script=sci_artte xt\&pid=S1413-81232012000200018>. Acesso em: 8 maio 2015 .
SEAE - SOCIEDADE ECOLÓGICA AMIGOS DE EMBU. Fonte Escola. [2013?]. Disponível em: <http://seaembu.org/seae/fonte-escola/>. Acesso em: 8 maio 2015 .

SOMERSET, S.; MARKWELL, K. Impact of a school-based food garden on attitudes and identification skills regarding vegetables and fruit: a 12-month intervention trial. Public Health Nutrition, v. 12, n. 2, p. 214-221, 2009. Disponível em: <http://journals.cambridge.org/action/displa yAbstract? fromPage=online \&aid $=3432368 \&$ fileId =S1368980oo8oo3327>. Acesso em: 8 maio 2015.

SUREMAIN, C.-É. de; KATZ, E. Introdução: modelos alimentares e recomposições sociais na América Latina. Anthropology of Food, n. S6, 2009. Disponível em: <http://aof.revues. org/6433>. Acesso em: 8 maio 2015.

SZYMANSKI, H. Entrevista reflexiva: um olhar psicológico sobre a entrevista em pesquisa. In: SZYMANSKI, H.; ALMEIDA, L. R.; PRANDINI, R. C. A. R. (Org.). A entrevista na pesquisa em educação: a prática reflexiva. 2. ed. Brasília, DF: Liber Livro, 2008. p. 9-61.

VEIGA-NETO, A. Pensar a escola como uma instituição que pelo menos garanta a manutenção das conquistas fundamentais da modernidade. In: COSTA, M. V. (Org.). A escola tem futuro? 2. ed. Rio de Janeiro: Lamparina, 2007. p. 97-118.

\section{Contribuição das autoras}

Coelho realizou a coleta dos dados e ambas as autoras trabalharam na concepção e no delineamento do estudo, na análise e interpretação dos dados, na redação do artigo, sua revisão crítica e na aprovação da versão final.

Recebido: 09/05/2015

Reapresentado: 28/03/2016

Aprovado: 08/04/2016 